\title{
Identidade e memória em Andamios de Mario Benedetti
}

\author{
Neiva Fernandes*
}

\begin{abstract}
Resumo: O presente trabalho visa a discussão a respeito da (re)construção do 'eu' através da memória. Neste sentido, ela cumpre um papel fundamental no resgate de um 'si mesmo' e também de um 'vir a ser' como sujeito social. Lacan destaca a memória como reveladora de alguns espaços importantes da história do sujeito, mesmo que isso venha a gerar conflitos internos. Do ponto de vista literário, e, nesse caso, a personagem Javier Montes, da obra de Mario Bendetti, Andamios, vem a ser aquele que ao voltar ao seu país de origem, Uruguai, procura resgatar seus papéis sociais através da rememorização para, então, neles, retomar sua identidade. A (re)construção do eu passa pelos antigos afetos abandonados na fuga do exílio. A retomada destes se dá em termos de lembranças e reencontros consigo mesmo e com um país que o esqueceu como sujeito social.
\end{abstract}

Palavras-chave: Memória; Identidade; Sujeito; (re)Construção.

\begin{abstract}
This article aims at discussing the (re)construction of the self through memory. In this sense, it fulfills an essential role concerning the recovery of "a self" and also of a social subject "to be". Lacan emphasizes that memory can unveil some important moments in the subject's history, even if this can lead to inner conflicts. From the literary point of view, Javier Montes, a character in the work Andamios, by Mario Benedetti, is the one who goes back to his motherland, Uruguay, trying to rescue his social roles through his remembrances, so that he can regain his identity. The (re)construction of the self has to do with previous affections abandoned after he went into exile. The retaking of these affections takes place in terms of personal memories and during new meetings with himself in a country that has forgotten him as a social subject.
\end{abstract}

Keywords: Memory; Identity; Subject;

(Re)construction.

As especificidades de cada país latino-americanos leva-nos a refletir sobre a manutenção da lembrança de fatos traumáticos através da representação literária, como as ditaduras do Cone Sul, por exemplo. Ao contrário dos demais países, o Brasil tem-se ocupado de outras questões que não esta. Temos vivido sempre de costas a nós mesmos e aos nossos vizinhos quando se trata de um assunto tão pertinente quanto o é a repressão política.

Revolver o passado não faz parte de nossa reflexão cultural, embora há que se dar mão a palmatória para eventos como o "V Fórum de Literatura Brasileira da UFRGS" que, segundos seus organizadores, buscam "avaliar com certo distanciamento o impacto do

\footnotetext{
* Neiva Fernandes é professora de Língua e Literaturas de Língua Espanhola na UNIJUI. Também é tradutora e professora de tradução. Suas últimas publicações são: "El no-lugar del yo en Mario Benedetti y Eduardo Galeano" Estudos de literatura brasileira contemporânea, Brasília, n.22, Brasília, jul./dez. 2003; "Primavera con una esquina rota, de Mario Benedetti e o exílio de cada um". Expressão: Memória, literatura e identidade nos países do MERCOSUL, [Santa Maria], n.2, jul/dez. 2002.
} 
autoritarismo sobre a literatura". A manutenção da memória e a consciência de que ela serve como um alerta para que tais regimes não se instalem nunca mais na América Latina, é algo que submete os escritores em geral, ao compromisso com a verdade e com o passado que não pode ser apagado tão facilmente. Portanto, obras como Andamios de Mario Benedetti não podem ser lidas como somente parte de sua história recente, nem como registros ficcionais inócuos à nossa condição de latino-americanos, mas sim como uma constante dessa mesma condição. E, não se trata aqui de nenhuma patologia individual ou social, mas simplesmente não se esquece porque não se quer esquecer.

O presente trabalho visa a discussão a respeito da (re)construção do 'eu' mediante a memória como cumpridora de um papel fundamental no resgate de um 'si mesmo' e também de um 'vir a ser' como sujeito social. Lacan destaca a memória como reveladora de alguns espaços importantes da história deste sujeito, mesmo que isso venha a gerar-lhe conflitos internos. A personagem, Javier Montes, após a volta do exílio a sua cidade natal, Montevidéu, depara-se com um país que já não é mais o mesmo, nem no espaço geográfico - como não poderia deixar de ser —, nem no âmbito social, posto que a máquina repressora empenhou-se em manter silenciada uma identidade coletiva por meio de uma desmemória pretendida como voluntária, induzida, a princípio, pela ditadura e, depois, por uma memória seletiva levada a cabo pelo governo de Julio María Sanguinetti, cujo discurso convida os uruguaios ao esquecimento total.

Cabe ressaltar que identidade e memória são inseparáveis, até porque, nesta última, as imagens atuam como co-autoras de uma identidade pessoal e intransferível; no entanto, na impossibilidade da rememoração, a memória opera no indivíduo como processo de desidentificação, posto que seu script não o conduz a lugar nenhum e nem o inscreve como ator principal de seu contexto.

Nas palavras de Benedetti, "el olvido está lleno de memória" e, nesse caso, acrescento que quem esquece seu passado está, de uma certa forma, condenado a revivê-lo em outras esferas, como a literatura, por exemplo.

Os anos 60 representaram, para a América Latina, uma nova consciência continental. O florescimento das letras hispano-americanas na segunda metade do século XX deveu-se, em parte, a um posicionamento sócio-político por parte de autores como Mario Benedetti, por exemplo, um dos representantes da generación de 48 que, entre tantos, compreendeu o que realmente queria dizer o termo latino-americano e suas relações com liberdade de expressão e comprometimento. Frente a uma literatura anterior que caracterizava-se pela dominação 
européia, não havia como dissociar literatura e transformações sociais. À problemática do individualismo, somou-se a do coletivismo. Conseqüentemente, as obras revelam um pacto entre a nação e o escritor, entre diversidade e identidades e, por extensão, entre a obra, o leitor e o contexto social de seu país. Nas palavras de Benedetti,

A América Latina continua sendo hoje um tema para seus artistas e intelectuais, porém ademais, constitui-se num problema. Problema para aqueles que o eludem; para aqueles que o afirmam e para aqueles que o negam; para aqueles que o assumem em seu ser mais íntimo e para aqueles que o examinam de longe; embora o binóculo seja parisiense, londrino ou romano, o olhar continua sendo inevitavelmente latino-americano. (1972, p. 366)

Considerando esta inevitabilidade, vale lembrar que, em Andamios, o autor não contradiz seu ponto de vista. A angústia do exilado, o retorno ao seu país, o sentimento de busca pelo que já foi e a atuação da memória são elementos de um mesmo tema: a (re)construção de um eu que insiste em não ser mais o mesmo. O inevitável aparece quando, em determinadas partes do livro, o autor situa seus personagens no contexto espanhol embora com o olhar voltado para a América Latina, conferindo-lhes um caráter que, se, por um lado, os desestabiliza como sujeitos, por outro leva-os a procurar seu ponto de referência e o fazer parte de algo que está distante e momentaneamente inacessível.

Para quem conhece a obra de Mario Benedetti e está informado a respeito de sua vida, Andamios não surpreende por permanecer coerente com seu posicionamento como escritor latino-americano em termos do resgate da memória e das instabilidades identitárias decorrentes da própria formação e do processo histórico de nosso continente.

Andamios trata do retorno de um exilado político ao seu país de origem, o Uruguai. Após a permanência de doze anos em Madri, Javier Montes volta a Montevidéu trazendo consigo uma bagagem de lembranças, solidão e esperança, retomando suas velhas amizades e tentando resgatar, através delas e da paisagem citadina, uma identidade que, a duras penas, percebe já não ser a mesma. Em Madri deixou a ex-mulher Raquel e a filha Camila com quem se corresponde regularmente. Depois de algum tempo, Javier revê seus irmãos que residem nos Estados Unidos, Gervasio e Fernanda e que, por sua vez, provocam-lhe um sentimento de tristeza, e repulsa pelo fato de tornarem-se cidadãos norte-americanos implicando, daí, na perda não só no sentido legal, mas também moral de sua condição de latino-americanos. Nesse ínterim, apaixona-se por Roccío, sua antiga companheira de clandestinidade e, mantém com ela, um relacionamento amoroso que só acaba com a morte deste personagem em um trágico acidente de carro e do qual Javier sobrevive. 
Esta é uma história que narra o exílio e o desexílio de alguém que procura resgatar seus papéis sociais por meio da rememorização, e, conseqüentemente, retomar suas identidades. No entanto, o retorno é um processo difícil e doloroso pois, é inevitável o reencontro com uma Montevidéu, que por sua vez, não é mais o mesma cujas lembranças e imagens permaneceram em sua memória. A dicotomia com a qual Javier tenta conviver resulta num estado angustiante de conflitos internos. Afinal, quem foi ele, na época da ditadura? Que cidade é essa que não o reconhece mais como sujeito social, o que para ele, significa estar em permanente luta pelos direitos fundamentais do homem e pela liberdade de expressão? O que encontra é uma Montevidéu desmemoriada onde as pessoas silenciam dando-lhe a impressão de que simplesmente esqueceram do que passou? Portanto, quem é agora Javier Montes? O que lhe cabe cumprir como novo cidadão de um mundo estranho e ao mesmo tempo conhecido e permanente nas imagens rememoradas? O que vale a pena recordar que possa contribuir para um outro dasein? Como conciliar memória válida com os traumas da separação e da volta?

Buscando evitar um choque frontal com a nova realidade, a personagem busca refúgio em uma casa de praia e de lá, aos poucos, vai reconstruindo, através das visitas dos antigos companheiros de luta e dos fragmentos do passado, um Javier militante e uma Montevidéu conhecida para, depois, no processo inverso, construir-se a si próprio neste novo mundo, andaime por andaime: "...tratar de asimilar un país que no es el mismo, y sobre todo comprender por qué yo tampoco soy el mismo." (p.15). Aos poucos, Javier vai recuperando a cidade através seu país. Dá-se conta do distanciamento que ele mesmo imputou-se, de que os antigos amigos ajudaram-no neste processo de reencontro e lentamente a construção se expande em direção a uma nova vida. Assim, "las voces del regreso y los rostros del regreso"(p. 47) estabelecem as pontes necessárias para as pazes consigo e com a cidade.

Como o Angelus Novus de Klee, seu olhar volta-se para o passado, para a catástrofe desencadeada durante a ditadura, mas de uma certa forma o impulsiona a olhar para a frente, a um futuro que agora Javier está disposto e preparado a enfrentar.

Benedetti, em seu prólogo, explica o significado do título. Andaimes e construção são indissociáveis porque sugerem compartilhamento; nesse sentido, a personagem valeu-se do passado e nele inscrevem-se os amigos, obviamente, para consolidar o processo de repatriação que lhe permitisse descobrir seu país pessoal. A narrativa surge como uma tentativa, por parte do autor, de retomar as origens de seu país e da América Latina face ao fenômeno globalização. Benedetti estabelece o diálogo que comporta a aceitação do outro, do 
estrangeiro fora e dentro do país. A personagem Javier experimenta a vivência de um novo estado de 'vir a ser' num país que agora se define como democrático; não sabe muito bem como conviver com a liberdade e, inclusive, na revisão que obriga-se a fazer ao reencontrar seu antigo torturador, o coronel Berenjano, depara-se com mais um dos fantasmas com os quais deve de exorcizar para, por fim, retomar a ação construtora. Segundo o autor, a democracia é um estado em construção contínua, cujo edifício jamais estará terminado. Um sistema sem um final possível.

A inquietude em torno dos temas de identidades e de memória ressalta o pertencer a algum lugar, à manutenção de uma unidade, embora diversa, uma possibilidade de mudança e recriação e também, por que não dizer, de reação contra a anulação de si e dos referentes identitários. Participar dessa inquietude não deixa de ser uma maneira que Mario Benedetti encontrou para reafirmar seu comprometimento social com a América Latina.

Toda a construção identitária por meio da memória implica na discussão preliminar do comprometimento. Portanto, Benedetti, com Andamios, resgata essa discussão. Assim, o retorno de Javier é o retorno interior e/ou geográfico de cada latino-americano quando tem em mente a necessidade de assumir seu lugar no continente ou fora dele.

\section{Referências}

BENEDETTI, Mario. Andamios. Madrid: Santillana, 1997.

Temas e problemas. In: MORENO, César Fernandes. América Latina em sua literatura. São Paulo: Perspectiva, UNESCO, 1972. 